\title{
La asamblea comunitaria en la resistencia a la minería. El caso de Tetela de Ocampo, México*
}

\author{
The community assembly in resisting mining. The case of Tetela \\ de Ocampo, Mexico
}

A assembleia comunitária na resistência à mineração. $\mathrm{O}$ caso de Tetela de Ocampo, México

María Carolina Restrepo Gómez**

\section{RESUMEN}

Este artículo explora desde el marco de la asamblea comunita-

Palabras clave: ria, cómo los sujetos en colectivo se sitúan en una resistencia y acción colectiva y a través de la defensa de sus territorios se encuentran y autodeminería, asamblea finen a partir de sus raíces y valores intersubjetivos. México ha comunitaria, registrado una creciente presencia de proyectos extractivos en deliberación, poblaciones tradicionalmente rurales, los cuales han generado resistencia. procesos de resistencia por parte de las comunidades. Estos procesos han implicado luchas desde espacios jurídicos, políticos y organizativos. Las comunidades han encontrado en la asamblea comunitaria un espacio para la consolidación y articulación de resistencias contra los proyectos extractivos en sus territorios. El análisis aterriza en el estudio de caso de la comunidad de Tetela de Ocampo en México y explora los hallazgos a partir de la teoría de la deliberación de Jürgen Habermas y Jon Elster.

\footnotetext{
* Este artículo es producto de una investigación de tesis de maestría titulada "La práctica de la deliberación en el proceso de toma de decisiones en la asamblea comunitaria en Tetela de Ocampo, Puebla (2014)" desarrollada en el Instituto de Ciencias de Gobierno y Desarrollo Estratégico de la Benemérita Universidad Autónoma de Puebla, México.

** Colombiana. Doctora en Ciencias de Gobierno y Política por la Benemérita Universidad Autónoma de Puebla. Colegio de Tlaxcala, Tlaxcala, México. restrepocarolina91@ gmail.com
} 


\begin{abstract}
This article explores, from the standpoint of the community assembly, how subjects collectively position themselves to resist and, through the defense of their territories, find and define themselves on the basis of their roots and intersubjective values. Mexico has witnessed a growing presence of extractive projects in traditionally rural populations, which have sparked resistance among local communities. These processes have implied struggles in legal, political and organizational spaces. The communities have found in the community assembly a space for consolidating and organizing resistance against extractive projects in their territories. The analysis focuses on the case study of the Tetela de Ocampo community in Mexico and explores the findings based on the deliberation theory of Jürgen Habermas and Jon Elster.
\end{abstract}

\section{RESUMO}

Este artigo explora, a partir da estrutura da assembleia comunitária, como os sujeitos se situam coletivamente em resistência e como se encontram e se definem com base em suas raízes e valores intersubjetivos através da defesa de seus territórios. O México registrou uma presença crescente de projetos extrativos em povoados tradicionalmente rurais, o que tem gerado processos de resistência por parte das comunidades. Estes processos provocaram lutas em espaços jurídicos, políticos e organizacionais. As comunidades encontraram na assembleia comunitária um espaço para a consolidação e a articulação da resistência contra projetos extrativistas em seus territórios. A análise se concentra no estudo de caso da comunidade de Tetela de Ocampo, no México, e explora as conclusões baseadas na teoria da deliberação de Jürgen Habermas e Jon Elster.
Keywords: collective action and mining, community assembly, deliberation, resistance.

Palavras-chave: ação coletiva e mineração, assembleia comunitária, deliberação, resistência. 


\section{Introducción}

Históricamente el campo en América Latina y específicamente en México, se ha visto inmerso en luchas sociales, las cuales han sido la expresión de demandas estructurales que no han sido resueltas por la vía democrática. De manera reciente, y sumada a la complejidad ya existente, económicamente los mercados internacionales han encontrado atractiva la explotación de sus recursos naturales, aumentando el registro de conflictos ambientales especialmente en comunidades rurales.

La extracción minera es una de las industrias que más ha propiciado el incremento de disputas por el territorio entre empresas propietarias de concesiones y los habitantes de las comunidades donde estas tienen lugar. Desde las comunidades se han cuestionado los efectos en el medio ambiente y en las dinámicas comunitarias, cuya vida y desenvolvimiento económico está ligado en su mayoría a los recursos naturales. En este contexto, en la medida que se otorgan concesiones a los particulares sobre recursos de pertenencia comunitaria sin incluirlas en las decisiones, es previsible su resistencia frente a dichos procesos.

En el caso de México, las concesiones mineras se incrementaron a partir de las políticas de libre mercado implementadas desde 1982 con el gobierno de Miguel de La Madrid, y con la reforma a la Ley de Minas en 1992, 1995 y 2005, que actualmente permite a empresas privadas la concesión de áreas para la explotación de minerales. Estas políticas que, en cierta medida, han sido generalizadas en la mayoría de los países de América Latina, convierten a México en uno de los países con mayor número de conflictos mineros, llegando estos a 54 conflictos hasta el año 2020 (Observatorio de Conflictos Mineros [OCMAL], 2020).

En este panorama nacional, el estado de Puebla ${ }^{1}$ cuenta con ocho conflictos mineros y, pese a que no tiene los principales yacimientos como los estados de Chihuahua, Zacatecas y Durango, es un territorio atractivo para el sector minero por su ubicación estratégica entre la Ciudad de México y el Golfo de México. Esto propició que entre 2014

1 Puebla ocupa el tercer lugar en el listado de conflictos mineros, después de Chihuahua con 13 conflictos y Zacatecas con 12. 
y 2016 se registraran 753 títulos correspondientes a 976.476 hectáreas, lo que equivale al $28,5 \%$ del territorio del estado con actividades de exploración y explotación minera (Clavijo, 2017). La mayoría de los conflictos se ubica en la región de la Sierra Norte de Puebla, donde se otorgaron concesiones principalmente para la explotación de oro a cielo abierto.

Los conflictos mineros en Puebla involucran 304 concesiones con una superficie de 245 mil 885 hectáreas (Bastidas et al., 2019) Los cuatro conflictos referidos en la zona son: 1) Almaden Minerals, en Ixtacamaxtitlán, para la explotación de cobre, oro y plata; 2) "El Aretón", en Tlatlauquitepec; 3) La mina "La Lupe" en el Municipio de Zautla; y 4) "Las Espejeras" ubicada en La Cañada en el Municipio de Tetela de Ocampo, donde se pretende extraer oro a cielo abierto (OCMAL, 2020).

Frente a esta problemática, las comunidades recurrieron a la discusión y distribución de la información en espacios comunitarios, apoyadas en la articulación con otras comunidades con conflictos similares. A partir de esto, se han consolidado ejercicios deliberativos para tomar decisiones como sujetos colectivos, lo que ha permitido a las comunidades fijar una postura de resistencia, apelado a tradiciones, usos, costumbres e identidades y crear espacios alternos de discusión.

En este proceso, escenarios de la comunicación comunitaria como la asamblea han tomado gran relevancia, ya que aunque ha sido un mecanismo utilizado de manera histórica para dirimir conflictos relacionado con el ejido ${ }^{2}$, en algunos casos las asambleas ahora se posicionan en la discusión referente a la incursión de proyectos de alto impacto en las comunidades y aglutinan a una diversidad de actores que no necesariamente están vinculados con la propiedad de la tierra. En este contexto, se entiende la asamblea como un espacio que puede responder a lógicas más cercanas a la deliberación que a la imposición y es quizá, en este sentido, uno de los espacios que permite entender la formación de una postura y el proceso de transformación de las voluntades individuales en una voluntad colectiva en el ámbito comunitario.

2 El ejido era contemplado en la legislación mexicana como el sistema de tenencia de tierras colectivas, sin posibilidad de dividirse ni venderse o heredar. La asamblea ejidal era considerada el máximo órgano en el que los ejidatarios tomaban decisiones acerca de las tierras. 
Es de destacar que en el estado de Puebla algunas comunidades se habían relacionado históricamente con la minería desde el periodo de la Colonia, pero en el esfuerzo colectivo de fortalecer el desarrollo agrícola y la consolidación del ecoturismo en la zona, se logró con el tiempo desvincular a las comunidades de la minería. Desde este contexto se explica que, en un inicio, las concesiones mineras no generaran mayor asombro en las poblaciones, y solo fue hasta la discusión a fondo de los proyectos extractivos - de los cuales algunos ya se encontraban en fase de exploración-, que se dimensionaron las implicaciones de la minería a cielo abierto ${ }^{3}$.

Se llevaron a cabo procesos comunitarios de discusión, distribución de la información y reflexión colectiva, los que encontraron en la asamblea comunitaria un espacio de convergencia y de consolidación de procesos deliberativos. En este sentido, la deliberación que atañe a los procesos de formación de resistencia frente a los proyectos extractivos, encuentra en la asamblea comunitaria una nueva vinculación, siendo entendida como "un espacio de toma de decisiones, en el que se puede observar el faccionalismo político, el conflicto y los acuerdos en una comunidad" (Sierra, 1987, p. 339). Es importante mencionar que la asamblea comunitaria es un espacio utilizado desde la proliferación de pequeñas comunidades rurales para la coordinación de procesos de producción y distribución alimentaria, y que ahora se posiciona como un escenario importante de la discusión de conflictos sociales y ambientales que involucran a todos los habitantes de un territorio.

\section{Descripción del conflicto minero en Tetela de Ocampo, Puebla}

Este artículo se focaliza en el estudio de caso del proceso de resistencia comunitaria al proyecto conocido como Las Espejeras en la Comunidad de Tetela de Ocampo, en la Sierra Norte del estado de Puebla, México. Las Espejeras cuenta con 17 concesiones que abarcan un total de 22.784 hectáreas. El proyecto pertenece a la empresa Minera San

3 La minería a cielo abierto consiste en la lixiviación del terreno mediante el uso de cianuro, mercurio y ácido sulfúrico para disolver los compuestos y obtener los minerales de la tierra (Asociación Geoinnova, 2020). 
Francisco del Oro S. A., filial de la minera Frisco, perteneciente al grupo mexicano Carso (Bastidas et al., 2019).

La concesión se encuentra en la comunidad de La Cañada, a cinco kilómetros del Municipio de Tetela de Ocampo. En el año 2013 Carso realizó 27 perforaciones con el permiso de la autoridad ambiental, lo que generó procesos de discusión y debate en la comunidad y para finales de ese año la disputa por el territorio escaló a la discusión regional y se consolidó un movimiento de resistencia que aglutinó a pobladores, líderes locales y organizaciones civiles de la Sierra Norte del estado.

Sin embargo, pese a que en la zona de La Cañada históricamente se ha explotado el coxcatlteo-cuitlatl (oro) desde antes de la Conquista y durante la época colonial, Las Espejeras planteaba un cambio en el proceso de extracción, pasando de la minería tradicional por túneles a la minería a cielo abierto, lo que amplificaba el impacto ambiental y las dinámicas sociales en el Municipio.

En octubre de 2013 la comunidad organizada en asambleas comunitarias exigió la realización de una consulta libre e informada donde los habitantes pudieran plasmar una postura en colectivo frente al proyecto minero, esto en el marco del acuerdo 169 de la Organización Internacional del Trabajo OIT, el cual contempla la realización de una consulta popular que garantice el derecho de las comunidades con un componente indígena a decidir respecto de sus territorios y el rumbo de sus comunidades. De este modo, el convenio exhorta a los Estados que lo ratifican a garantizar el derecho de los pueblos indígenas y tribales a fijar sus propias prioridades en cuanto a su desarrollo económico, social y cultural.

Con la finalidad de contextualizar el caso de estudio analizado, es necesario mencionar que el Municipio de Tetela de Ocampo está ubicado en la parte norte del estado de Puebla y a 221 kilómetros de la Ciudad de México (Instituto para el Federalismo y el Desarrollo Municipal [INAFED], 2020). El Municipio cuenta con una población de 25.793 habitantes (Secretaría de Desarrollo Social [SEDESOL], 2020), distribuidos en 85 localidades, de las cuales 84 son rurales y una concentración del $17 \%$ en la cabecera municipal (Martínez, 2012). En cuanto a la descripción sociodemográfica, Tetela está catalogado como un Municipio 
con alto grado de marginación, donde el 78,20\% de la población está en situación de pobreza y el 18,37\% de los habitantes son vulnerables por carencia social (SEDESOL, 2020).

En cuanto a la ocupación principal de la comunidad, se identifica como actividad primaria la agricultura, específicamente la producción de maíz, durazno y aguacate y de manera reciente el incremento de servicios turísticos. Tetela de Ocampo está catalogado como un $\mathrm{Mu}-$ nicipio con presencia indígena, donde el 22,21\% de sus habitantes son hablantes de una lengua indígena (SEDESOL, 2020), predominantemente el náhuatl ${ }^{4}$.

El objetivo central de la investigación fue analizar los procesos deliberativos que tienen lugar en la asamblea y las percepciones que se tejen alrededor de esta. Se dimensiona la comunidad como el actor preponderante en la formación de una postura de resistencia frente a un conflicto minero, con prioridad en el registro de las narrativas construidas en torno a lo comunitario y al territorio.

A continuación, se esquematizan los distintos actores que configuran el conflicto en el Municipio y entre los que se tejen las tensiones y relaciones que se reflejan en la asamblea comunitaria.

4 Frente a un conflicto de naturaleza territorial y con componente indígena, el convenio 169 de la Organización Internacional del Trabajo, establece el derecho a la consulta libre, previa e informada, para que las comunidades decidan respecto de la procedencia o no de los proyectos asentados en sus territorios. Cuando esta condición no está garantizada, las comunidades se enfocan en la resistencia por medios comunitarios. 
Figura 1.

Mapa de actores en el conflicto minero de Tetela de Ocampo

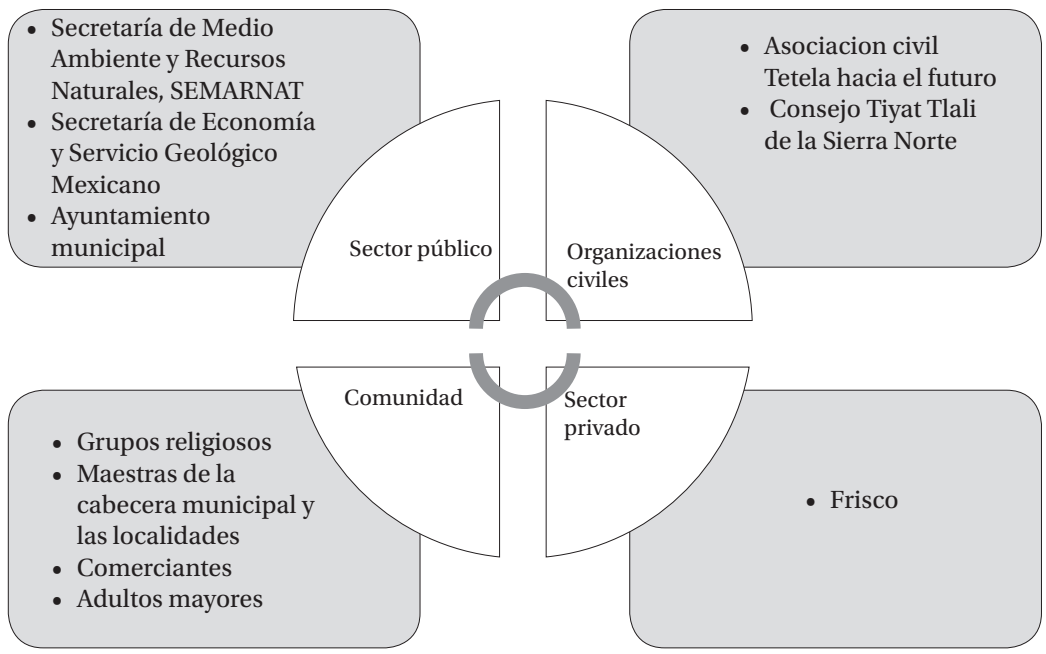

Fuente: Elaboración propia.

A partir de los actores y los espacio de la asamblea se desarrolló una estrategia metodológica que permitiera el registro de las narrativas, las dinámicas sociales y la construcción de decisiones colectivas frente al proyecto minero. Luego de ello, se privilegió la investigación de tipo cualitativa en el estudio de caso, centrándose en los procesos comunicativos de los actores para recuperar las experiencias de la organización de la resistencia e identificar las reflexiones colectivas en torno a la asamblea.

\section{Metodología}

Se tomó como variable de investigación la deliberación, entendida como el acto en el que se alternan distintos razonamientos y después se alcanzan decisiones finales atravesadas por el supuesto de racionalidad, igualdad y libertad (Habermas, 2011). Frente a esta definición se agregaron las visiones de Elster (2001) que sostiene que la deliberación requiere de "la existencia de valores compartidos y del consenso, así como de los acuerdos simbólicos del lenguaje, lo verbal y lo corporal que propicien el diálogo" (p. 129).

En contraste, como variable dependiente, se estableció la toma de decisiones colectivas que, "implica un uso público de la razón, que fomenta la comprensión ciudadana de la sociedad y los principios que la 
regulan" (Bohman, 2000, p. 25). A partir de los postulados teóricos se realizó una operacionalización que contempló los siguientes elementos a indagar expuestos en la Tabla 1.

Tabla 1

Operacionalización de las variables

\begin{tabular}{ll}
\hline Deliberación & Toma de decisiones colectivas \\
\hline - Distribución de la información. & - Decisiones de carácter \\
- Gestión del conflicto. & organizativo. \\
- Influencia en la opinión pública. & - Decisiones sobre difusión y \\
- Generación de propuestas & visibilidad de la problemática. \\
$\quad$ alternas a de la esfera política. & - Decisiones de tipo legal. \\
- La influencia de la identidad. & - Percepción de consenso. \\
\hline
\end{tabular}

Fuente: Elaboración propia sobre la base de Acosta y Díaz (2014).

En cuanto a la unidad de análisis se privilegió la asamblea, ya que es de especial interés para observar los ejercicios deliberativos que pueden conducir al establecimiento de acuerdos más estables y contribuir a la transformación de preferencias, la generación de alternativas diferentes de las surgidas desde la esfera política y la formación de una postura en colectivo.

En cuanto a las técnicas de recolección de información se realizó observación no participante, entrevistas semiestructuradas y un monitoreo de medios que permitiera indagar acerca de cada uno de los elementos planteados en la operacionalización de variables.

En el caso de la observación no participante, esta se planteó como la técnica adecuada para la caracterización del tipo de asambleas llevadas a cabo en la comunidad. Una de las premisas más importantes fue poder establecer la distinción de asambleas deliberativas o de ratificación discutidas por Sierra (1987) frente a las llevadas a cabo en el proceso de resistencia. Se presenciaron las asambleas comunitarias realizadas durante el año 2014 en el Municipio de Tetela de Ocampo donde se registraron los hechos a manera de bitácora. A partir de esta técnica se pudieron establecer los patrones de debate, las dinámicas de las intervenciones y los aspectos simbólicos que dotan de singularidad al caso de estudio.

En cuanto a las entrevistas semiestructuradas, como señala Álvarez-Gayou (2013) esta técnica permite dar cuenta de la vinculación de 
los seres humanos con énfasis en la experiencia y su relación con personas, sucesos y situaciones. En este sentido, se privilegiaron las visiones de los participantes en las asambleas, indagando respecto de los motivos de vinculación y la forma en la que se construye el consenso.

Para la identificación de los perfiles a entrevistar se utilizó la técnica de muestreo por bola de nieve, donde se identificaron a los participantes clave y, a partir de su referencia, se fue ampliando la diversidad de perfiles. Se realizó un total de siete entrevistas semiestructuradas con los perfiles expuestos a continuación en la Tabla $2^{5}$.

Tabla 2

Identificación de los perfiles a entrevistar

\begin{tabular}{ll}
\hline Descripción e identificación de la perspectiva del entrevistado \\
\hline Entrevistado 1 & $\begin{array}{l}\text { Líder comunitario y miembro de la asociación civil } \\
\text { "Tetela hacia el futuro". Propulsor de foros regionales y } \\
\text { asambleas municipales. Es referido continuamente como } \\
\text { una autoridad moral en la comunidad. }\end{array}$ \\
\hline Entrevistado 2 & $\begin{array}{l}\text { Comerciante de la zona centro, asistente regular desde el } \\
\text { año 2013 a las asambleas comunitarias. Enlace entre el } \\
\text { conflicto minero en el Municipio de Ixtacamaxtitlán y el } \\
\text { de Tetela de Ocampo. }\end{array}$ \\
\hline Entrevistado 3 & $\begin{array}{l}\text { Docente jubilada, encargada de las discusiones en torno a } \\
\text { la minería en espacios escolares. La entrevistada presenta } \\
\text { una postura crítica de las asambleas. }\end{array}$ \\
\hline Entrevistado 4 & $\begin{array}{l}\text { Ama de casa y miembro activo de la asociación “Tetela } \\
\text { hacia el futuro". Asistente regular a las asambleas } \\
\text { comunitarias desde el año 2012. }\end{array}$ \\
\hline Entrevistado 5 & $\begin{array}{l}\text { Participante en las asambleas desde el año 2012. Enlace } \\
\text { entre las autoridades formales del Municipio y las } \\
\text { asambleas comunitarias. }\end{array}$ \\
\hline Entrevistado 6 & $\begin{array}{l}\text { Abogado residente en el Municipio, encargado de las } \\
\text { gestiones legales fruto de las asambleas comunitarias. } \\
\text { Informante clave en cuanto a las decisiones de tipo legal. }\end{array}$ \\
\hline Entrevistado 7 & $\begin{array}{l}\text { Agricultor joven, asistente regular a las asambleas } \\
\text { comunitarias desde el año 2012. }\end{array}$ \\
\hline & 2016).
\end{tabular}

Fuente: Restrepo (2016).

5 Debido a restricciones de tiempo y espacio, no fue posible entrevistar a personas que apoyaran abiertamente el establecimiento de la minera. La agenda de investigación futura debería recabar las posturas de estas personas que si bien participaron en las asambleas comunitarias, no tomaron la palabra, no se involucraron en la organización de la asamblea, o no promovieron convocatorias para asistir al resto de la comunidad. 
En relación con el monitoreo de medios, de manera complementaria se realizó el registro de la prensa local del año 2012, año durante el cual fueron mayormente difundidos por medios locales los acuerdos fruto de las asambleas. Se realizó esta técnica con la finalidad de rastrear cómo los acuerdos establecidos en la asamblea tuvieron resonancia en la discusión de la resistencia a la minería en la región.

A partir de la propuesta metodológica antes descrita se establecieron hallazgos en tres sentidos: 1) discusión de las asambleas comunitarias en términos conceptuales y las dinámicas que adquiere en el proceso de resistencia a la minería en Tetela de Ocampo; 2) hallazgos en cuanto al análisis de los procesos deliberativos que tienen lugar en la asamblea comunitaria; y 3) exposición de apuntes referidos a las dimensiones culturales específicas de la comunidad, que dotan de singularidad el caso de estudio.

\section{Resultados}

\section{Asamblea comunitaria: vieja figura, nuevas articulaciones}

En el ámbito urbano es común observar la consolidación de las resistencias a partir de plataformas apoyadas en las redes sociales o fruto de disertaciones en espacios dedicados a la discusión de las distintas problemáticas de la sociedad, como lo son las universidades o los espacios de la sociedad civil organizada. En contraste, cuando la conflictividad se inserta en el ámbito rural, la formación de la resistencia se ve anclada a viejas figuras que han fungido históricamente como espacios de construcción colectiva. Este es el caso de la asamblea comunitaria, conocida en el ámbito rural para la administración del ejido y que es actualmente ha fungida como un mecanismo articulador para la defensa de los territorios frente a la creciente problemática de los proyectos extractivos en algunos Municipios en México.

Si bien en ocasiones en la asamblea podrían presentarse problemáticas asociadas con la localidad, la producción y la distribución agraria, en los procesos de resistencia en los territorios esta alude a dinámicas articuladas y ligadas a otros procesos nacionales o internacionales. De esta manera, la organización se entiende como el tratamiento de los asuntos que no solo se circunscribe estrictamente a la localidad, sino que la trasciende, y la lleva a sus límites, exigiendo lograr consensos 
más elaborados discursivamente, porque de ello dependen decisiones más consensuadas que ponen en duda la supervivencia de la localidad a la cual responde la asamblea comunitaria (Restrepo, 2016).

Desde esta perspectiva, la asamblea comunitaria representa un "espacio de convergencia de lo diverso, donde usualmente se dirime el conflicto y se toman decisiones con mayor consenso" (Velásquez, 2011, p. 329). En esta conceptualización, se propone una clasificación basada en el criterio de veracidad, donde pueden registrarse asambleas de ratificación o simbólicas y asambleas de carácter deliberativo.

En las asambleas de ratificación o simbólicas estas tienen por finalidad exponer acuerdos pactados de manera previa y que solo necesitan el reconocimiento formal para contar con legitimidad. En contraste, las asambleas de carácter deliberativo, son las que contienen

la característica principal de la interacción política, y es donde se puede apreciar con mayor nitidez el grado de participación de la sociedad, el nivel de acuerdos en torno a las prácticas de comunicación, y si tales acuerdos están determinados por una discusión en la que pueden intervenir todos los participantes con plena libertad. (Velásquez, 2011, p. 329).

Las asambleas que tienen prelación en esta investigación, son las de carácter deliberativo que, según Velásquez (2011):

Expresan la conflictividad o el faccionalismo político; es decir, la puesta en escena de actitudes individuales y colectivas frente a los proyectos sociales que determinarán el destino del Pueblo. Este carácter deliberativo determina el tiempo de duración de una asamblea, que en ocasiones puede llevar todo un día. (p. 341).

Con la finalidad de clarificar la distinción conceptual se exponen las principales características de las asambleas en la Tabla 3:

Tabla 3

Tipos de asamblea

\begin{tabular}{ll}
\hline Deliberativa & No deliberativa \\
\hline - Patrón de debate trazado por la & - Asambleas previas que la convierten \\
costumbre. & en asamblea de ratificación. \\
- Asambleas por sección y & Ratificaciones de negociaciones \\
posteriormente plenaria. & previas. \\
\hline
\end{tabular}

Fuente: Elaboración propia a partir de la información de Velásquez (2011). 
Como se mencionó con anterioridad, la asamblea ha sido un mecanismo utilizado por las comunidades rurales como la forma de tomar decisiones respecto de la propiedad, o bien, acerca de intereses colectivos. En México con la institucionalización del ejido, la asamblea comunitaria también fue reconocida ante la Constitución Política, lo cual la dotó de legitimidad entre los miembros de las comunidades, además de percibirse como la forma más cercana de participación y de ejercicio efectivo de toma de decisiones en el ámbito local.

Existe una diversidad en cuanto a las interacciones específicas que se pueden dar en las asambleas comunitarias como espacio político. Al respecto, María Teresa Sierra (1987) establece los siguientes patrones de reunión y debate que pueden aglomerar ciertos patrones comunes en algunas asambleas:

Tabla 4

Patrones de la asamblea

\begin{tabular}{|c|c|}
\hline Patrón reunión & Patrón debate \\
\hline $\begin{array}{l}\text { 1. Convocatoria. } \\
\text { 2. Preparativos y comisiones. } \\
\text { 3. Instalación formal de la } \\
\text { asamblea. } \\
\text { 4. Instalación del presídium. } \\
\text { 5. Lectura del orden del día. } \\
\text { 6. Instalación de la mesa de debate. } \\
\text { 7. Pase de lista. } \\
\text { 8. Postulación de los cargos. } \\
\text { 9. Votación. } \\
\text { 10.Escrutinio. } \\
\text { 11.Firma de acta. } \\
\text { 12.Clausura. }\end{array}$ & $\begin{array}{l}\text { 1. Designación de los candidatos o } \\
\text { propuestas. } \\
\text { 2. Ratificación o discusión acerca } \\
\text { del procedimiento de elección. } \\
\text { 3. Ratificación o discusión respecto } \\
\text { de los procedimientos de } \\
\text { votación. } \\
\text { 4. Presentación de los designados o } \\
\text { postulados como candidatos. } \\
\text { 5. Planteamiento a favor o en contra } \\
\text { de los candidatos. } \\
\text { 6. Contraargumentaciones. } \\
\text { 7. Discurso de los candidatos. } \\
\text { 8. Votaciones en cuanto a los } \\
\text { acuerdos. }\end{array}$ \\
\hline
\end{tabular}

Fuente: Sierra (1987, p. 336).

Para el caso de Tetela de Ocampo, las asambleas deliberativas comparten ciertos aspectos de los patrones de reunión y de debate planteados por Sierra (1987). En el marco de la resistencia en el Municipio de Tetela de Ocampo se llevaron a cabo asambleas desde el año 2012, las cuales contaron con una diversidad de asistentes entre los que se destacan miembros de asociaciones civiles vinculadas a la protección del medio ambiente, líderes comunitarios, habitantes del Municipio y 
de otros con conflictos que involucran el territorio. Las asambleas con mayor afluencia de asistentes son la que conmemoran la resistencia y que generalmente están acompañadas de marchas de protesta y celebraciones comunitarias.

A partir de la observación no participante, se establecieron los siguientes patrones de convocatoria y debate:

Tabla 5

Patrones de la asamblea en Tetela de Ocampo

\begin{tabular}{|c|c|}
\hline Patrón de reunión & Patrón de debate \\
\hline $\begin{array}{l}\text { - Convocatoria a través de medios } \\
\text { tradicionales como el perifoneo, la radio y } \\
\text { comunicaciones escritas. } \\
\text { - Preparativos y comisiones. } \\
\text { - Recorrido del centro del Municipio a la } \\
\text { zona concesionada en distintos medios de } \\
\text { transporte. } \\
\text { - Encuentro frente a la iglesia donde se } \\
\text { realiza la discusión (se cuenta con material } \\
\text { tecnológico para realizar las intervenciones, } \\
\text { micrófonos y apoyos visuales). Para la } \\
\text { comunidad la vinculación religiosa a la } \\
\text { resistencia es muy significativa. } \\
\text { - Ritual a la tierra. } \\
\text { Clausura: las personas toman las ofrendas } \\
\text { dadas a la tierra y las llevan consigo (flores, } \\
\text { agua, pulque }{ }^{6} \text {, entre otras). }\end{array}$ & $\begin{array}{l}\text { 1. Exposición de aspectos } \\
\text { relacionados con la } \\
\text { afectación del proyecto } \\
\text { minero. } \\
\text { 2. Contraargumentación. } \\
\text { 3. Discurso de actores } \\
\text { involucrados en los } \\
\text { distintos ámbitos de la } \\
\text { resistencia (jurídica, social, } \\
\text { medios de comunicación). } \\
\text { 4. Elaboración de acuerdos. } \\
\text { 5. Asignación de } \\
\text { compromisos a mano } \\
\text { alzada. } \\
\text { 6. Actividades de } \\
\text { esparcimiento. }\end{array}$ \\
\hline
\end{tabular}

Fuente: Elaboración propia.

En cuanto a las dinámicas particulares de las asambleas comunitarias en Tetela de Ocampo, se destaca la participación de las mujeres de la comunidad, no solo en el proceso organizativo, sino también en el debate que tiene lugar en las asambleas. Para el caso de Tetela se refuta lo expuesto por Máriam Martínez (2010) en cuanto al papel de la mujer en los procesos deliberativos en las asambleas, donde plantea que "tanto mujeres como chicas tienden a hablar menos, y cuando lo hacen, con frecuencia es para formular preguntas o expresar dudas, antes que para establecer con contundencia un argumento" (p. 11) .

$6 \quad$ El Municipio tiene una población dispersa en un amplio territorio, lo que implica el desplazamiento de personas para convocar a los de áreas más lejanas; actividad que es llevada a cabo por las maestras de la comunidad. 
En los debates tienen una importante presencia las personas de mayor edad de la comunidad, donde el liderazgo tiene un anclaje moral. En contraste, la participación de los jóvenes es escasa y con poco involucramiento en el proceso de deliberación. Esta situación representa uno de los grandes retos para el proceso de resistencia en Tetela de Ocampo. El Municipio es considerado por la Comisión Nacional para el Desarrollo de los Pueblos Indígenas (CNDPI) como un Municipio expulsor de migrantes, donde hay un importante flujo migratorio de jóvenes a Estados Unidos, lo que dificulta el proceso de integración de estos a la asamblea comunitaria (CNDPI, 2000).

\section{La resistencia a través de la deliberación}

Actualmente las sociedades presentan serias crisis a partir de la democracia representativa fincada en actores colectivos y en los partidos políticos. La representatividad de las demandas sociales, los cambios socioculturales y las nuevas formas de expresión de lo político, encuentran espacios reducidos de expresión en la democracia competitiva o procedimental. Frente a esta crisis política, se han elaborado esquemas de reinterpretación de la democracia, donde la ciudadanía tiene un papel mucho más activo en la consecución de las soluciones sociales, pero su inclusión se ve socavada si no se abren espacios de interacción. Es en este punto donde se hace una apuesta por la deliberación y sus espacios.

Se parte de la idea que la deliberación es un proceso que exige la adopción de decisiones colectivas y democráticas que "incluyan la participación de todos los afectados por la decisión o sus representantes, y un elemento deliberativo, que establece la argumentación racional e imparcial como criterio para la decisión política" (Elster, 2001, p. 21). La deliberación también implica que no hay una visión única de lo político, donde hay una diversidad de intereses donde a partir de la inclusión de los actores se pueden construir acuerdos con mayor estabilidad.

Por su parte, Maldonado sostiene que la deliberación ha sido la opción de un modelo capaz de transformar las sociedades a través de la reflexión de todos los actores que la componen.

La democracia deliberativa defiende la necesidad de reforzar la legitimidad democrática de las decisiones colectivas mediante la ar- 
ticulación de una interacción pública de las preferencias individuales, que estimula el debate en torno a las concepciones del bien, y la cristalización argumentativa del bien público. (Maldonado, 2007, p. 37).

Desde esta perspectiva teórica "la política se presenta como una actividad esencialmente cooperativa, donde el conflicto es reducido a través de la deliberación" (Maldonado, 2007, p. 37). A partir de los procesos deliberativos en las asambleas comunitarias, según Galdós (2006), las decisiones colectivas son más probables de ser registradas en comunidades con una fuerte identificación social y en una base territorial. El contexto de la investigación está enmarcado en esta idea de construcción de decisiones colectivas, ya que cumple con características como la proximidad territorial, los valores compartidos y cierta homogeneidad entre la población, factores que generan las condiciones propicias para una situación de decisión colectiva como la que plantea (Galdós 2006).

Mansbridge (1983) establece que "existe deliberación en todos los espacios sociales, desde el diálogo cotidiano informal que se establece con los vecinos, hasta los espacios políticos comunes como las asambleas comunitarias" (p.45). Se comparte este postulado y, a pesar de que la investigación se centra en las interacciones que tienen lugar en las asambleas comunitarias, las decisiones colectivas son multifactoriales y tienen lugar en múltiples espacios. En Tetela las interacciones en las fiestas patronales, el mercado, la iglesia, etc., tienen un contenido político y también en esos espacios se construyen las posturas de resistencia.

Para dicha comunidad, el análisis de procesos deliberativos evidencia construcciones de consenso, pero este no es forjado a través de un esquema racional o del mejor argumento, sino que las intervenciones y la construcción de las decisiones se produce a partir de factores

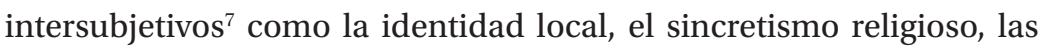
esferas sociales rutinarias del mundo, de la vida ${ }^{8}$, que vienen a reforzar o socavar los acuerdos de las asambleas comunitarias, lo que coincide con la idea de Elster (2001) en cuanto a la importancia de los valores

$7 \quad$ Entendidos como los valores compartidos entre los actores.

8 Las interacciones que se dan en espacios como el mercado, la iglesia y la escuela. 
compartidos y acuerdos simbólicos del lenguaje, lo verbal y lo corporal, como condiciones propicias para la existencia del diálogo.

Como se mencionó anteriormente, Laiba Galdós (2006) plantea que, con la finalidad de entender la incidencia de la deliberación, se deben considerar aspectos como: la distribución de la información, la gestión del conflicto, la influencia en la opinión pública, la generación de propuestas alternas a la de la esfera política y la influencia de la identidad.

En atención a estos aspectos, en el caso de estudio se evidenció que los procesos deliberativos en la asamblea contribuyeron a:

- Una distribución de la información acerca de los impactos del cambio de técnica de explotación de minería por túneles a cielo abierto, la difusión del acceso que tenía la comunidad a la consulta popular, las implicaciones nacionales de los procesos de explotación minera y su impacto en la cotidianidad de los pueblos. En cuanto a este aspecto uno de los entrevistados argumentó lo siguiente:

Se empaparon de información, se nutrieron para que fuéramos nosotros a comunidades, fueron muchos compañeros, no nada más yo, iban muchos hombres, mujeres. Sobre todo, la mujer aquí ha tenido una gran participación, y son las que llevaron esta información a muchas comunidades, para hacerle saber a la gente, que estamos amenazados. (Líder comunitario).

- En la asamblea comunitaria se llevaron a cabo diferentes sesiones de negociación con representantes de organismos estatales, representantes de la concesión minera y líderes de resistencias similares, además de las negociaciones internas entre los miembros de la comunidad (Gestión del conflicto). En este sentido uno de los entrevistados sostuvo:

Bueno, en los acuerdos que nosotros tenemos, se resuelven bajo votación, o sea " $i$ saben qué?, miren, la propuesta o los problemas, es este, señores ¿qué deciden?, ¿qué hacemos?, ¿qué es lo que nos conviene?", entonces, bajo votación, decidimos y llevamos acuerdo, nosotros presentamos el problema que se esté dando, y lo decidimos a través de todo el grupo y las diferentes organizaciones y las diferentes regiones y los diferentes pueblos, hemos estado muy en acuerdo. (Asistente a las asambleas). 
- Las discusiones en las asambleas lograron trascender a los medios de comunicación e insertar el debate acerca de la resistencia a los proyectos extractivos en el ámbito estatal y nacional. A través del monitoreo de medios realizado en el mes del anuncio del rechazo al proyecto minero (julio de 2012), se registró un total de doce noticias publicadas respecto de la resistencia en periódicos impresos; un número considerable, teniendo en cuenta que julio de 2012 fue un mes electoral, donde la agenda mediática estaba enfocada en los actos de los candidatos a la presidencia de la República, las manifestaciones del movimiento \#yosoy132 y el alza del huevo a nivel nacional (La influencia en la opinión pública).

- En cuanto a la generación de proyectos alternativos, del movimiento de resistencia emanó la propuesta referente al desarrollo de un plan territorial que permitiera el ordenamiento del Municipio y la protección de áreas con miras al fortalecimiento del ecoturismo, visualizando a este último como un ingreso económico importante para el Municipio (Generación de propuestas alternas).

- La identidad fue uno de los aspectos que estuvo presente en la formación de una postura de resistencia. Tetela de Ocampo fue determinante en la batalla del 5 de mayo de 1862 y esto le otorgó el título de "heroica". Este componente histórico ha estado presente en la resistencia, donde se hace constante apelación a la memoria histórica de la comunidad. Por otra parte, el conflicto permitió entender y reencontrar la raíz indígena a partir del vínculo con la tierra (La influencia de la identidad). En este último punto una de las entrevistadas - al cuestionarle acerca de los motivos que la llevaron a involucrarse con el movimiento de resistencia-, comentó: "yo creo que, porque nos llegan al corazón, porque están de por medio los hijos, tu familia, tu patrimonio, aquí lo tienes, aquí lo hiciste, aquí trabajaste". (Maestra).

Otro de los asistentes a la asamblea comunitaria señaló que:

Un grupo puede hacer mucho, pero una persona qué puede hacer, pero no, dentro de mi conciencia yo sentía que no, pero cuando empecé a ir a los foros dije "María ponte a trabajar y no le pares que esto no es de un día para otro", ya no me espanto, no me da susto, me siento con fuerza porque todos nos empezamos a unir, andábamos varios luchando pero no nos cono- 
cíamos, cada quien por su lado, pero era bien difícil porque no sabíamos quién andaba en la lucha. (Asistente a las asambleas).

A partir de los procesos de deliberación y la contribución de estos a los distintos aspectos de la gestión del conflicto, también fueron evidentes aspectos que dotan de singularidad a las asambleas comunitarias en Tetela de Ocampo y que hacen parte del sistema de creencias de la comunidad.

\section{El sincretismo religioso, el componente étnico y el territorio en el marco de la asamblea comunitaria}

Dentro de los aspectos que inciden en la fijación de una postura de resistencia, se encuentra la intersubjetividad, que hace referencia a los valores y referentes identitarios que son compartidos por un grupo social y que permite que los miembros puedan entablar intercambios argumentativos con niveles de significancia similares en torno a ciertas esferas de la vida. Ejemplos de esto para el caso de Tetela de Ocampo, podrían ser los valores comunes que se le asignan a aspectos como los acuerdos verbales, el vínculo emotivo con los referentes del paisaje que delimitan la idea de territorio y el significado de resistencia en términos históricos.

Por su parte, en la asamblea comunitaria también se hace evidente el sistema de creencias de la comunidad: el Municipio es mayoritariamente católico y, al mismo tiempo, hay una importante cosmovisión marcada por el grupo Nahua. En este sentido, en las asambleas hay un valor simbólico relevante de los elementos religiosos, especialmente en las asambleas conmemorativas de la resistencia a través de la presencia del sacerdote de la comunidad, como también del chamán.

Según María Ana Portal (1997), el análisis de lo religioso implica necesariamente "el aspecto de creencias, de la concepción mítica del mundo y la dimensión social del fenómeno" (p. 54). Para los participantes de las asambleas las dimensiones de pasado y futuro a partir del territorio coinciden con lo que Espejel (2012) sostiene en cuanto a la idea de futuro exaltado:

Durante mucho tiempo el futuro fue, y en muchos casos sigue siendo, promesa de progreso y desarrollo. Se exaltaba la confianza en un estilo de vida y valores que inexorablemente llevarían a la hu- 
manidad al mejor de los estados posibles. El paso irreversible del tiempo no ha dejado dudas, nos ubicamos hoy en el peor de los escenarios posibles. La superación de esta promesa de futuro es condición indispensable de la búsqueda de alternativas utópicas y a la vez realistas. (p. 215).

Por otra parte, en la comunidad se llevan a cabo rituales luego de las asambleas comunitarias. Se trata de un espacio y momento cargados de simbolismo, que desde la experiencia de los participantes se han convertido en generadores de unidad entre los miembros y de reencuentro como comunidad. En este sentido, Portal (1997) sostiene que "El rito es una práctica social repetitiva, formalizada y especial que permite ordenar, recrear, reproducir y actualizar las representaciones simbólicas y las relaciones sociales en un tiempo y un espacio prefijado y reconocidos socialmente" (p. 67). Las intervenciones registradas en la asamblea en su mayoría contenían una fuerte carga emotiva, lo que avivaba constantemente a los participantes a exclamar repetidas frases acerca de la resistencia; además, la gran mayoría llevó consigo banderas o carteles que hacían alusión a esta postura.

En Tetela la defensa del territorio no se produce en un sentido estrictamente geográfico, sino que este se concibe en un sentido cultural e identitario con referente al pasado y al futuro. Según Silva (1992):

los territorios fueron y siguen siendo un espacio donde habitamos con los nuestros, donde el recuerdo del antepasado y la evocación del futuro permite referenciarlo como un lograr que aquel nombró con ciertos límites geográficos y simbólicos. Nombrar el territorio es asumirlo como una extensión lingüística e imaginaria. (p. 48).

En la comunidad, los cerros y el agua tienen una profunda vinculación con la idea de que la tierra es la madre, de modo que desde esta perspectiva la pérdida del territorio es semejante a perder la raíz y la familia.

\section{Conclusiones}

A partir de la implementación de políticas neoliberales, se ha dado un incremento de las concesiones mineras en América Latina. Con la primacía de la lógica de mercado, empresas nacionales y de diversas partes del mundo, especialmente de lugares con marcos regulatorios 
muy restrictivos respecto de sus territorios, encontraron en México y en la Sierra Poblana lugares propicios para llevar a cabo proyectos extractivos de gran alcance. Las empresas con numerosas concesiones mineras afrontaron importantes procesos de resistencia que han puesto en evidencia la ausencia del Estado como ente regulador y garante de los derechos de autodeterminación de los habitantes y sus territorios.

Así mismo, los conflictos por el territorio han expuesto interesantes fenómenos comunicativos contrapuestos. Por un lado, decisiones verticales por parte de las instituciones y las empresas propietarias de las concesiones, y por otro, la deliberación como mecanismo utilizado por las comunidades para la construcción de acuerdos para mantenerse en resistencia. Un mecanismo frecuentemente utilizado en el marco de estos procesos de resistencia es la asamblea comunitaria, la cual plantea lógicas alternas para la discusión de lo que atañe al territorio, permitiendo una mayor distribución de la información en cuanto a aspectos tales como la legislación, el replanteamiento de cuestiones técnicas de la explotación o los posibles cambios de las dinámicas sociales que implica la industria minera. En algunos contextos a través de la asamblea comunitaria se ha logrado la articulación de procesos de resistencia similares que han propiciado la transferencia de conocimiento de este tipo de luchas y la consolidación de consejos regionales y asociaciones civiles enfocadas en apoyar a comunidades afectadas por procesos de despojo del territorio.

Cada vez es más frecuente el uso del concepto de deliberación en los discursos políticos, pero es enunciado sin entender de manera minuciosa sus dimensiones. Una limitación que pretende destacar la investigación es la generalización en cuanto a los contextos y las condiciones necesarias para que se pueda observar una genuina deliberación.

Autores como Elster (2001), Galdós (2006) y Habermas (1992) parten de la premisa que la toma de decisiones será más estable y legítima si procede de procesos deliberativos. Sin embargo, a pesar de lo vasto y profundo que se puede analizar en cuanto a las bondades y potencialidades de la deliberación en la toma de decisiones, existe escasa investigación empírica al respecto. No obstante el idealismo de la teoría para indicar lo normativo de la democracia en distintas esferas, la 
teoría deliberativa sigue siendo un marco de referencia para entender los procesos de decisión colectiva.

En ese contexto, a partir de los hallazgos obtenidos en el caso de Tetela de Ocampo se puede concluir que las decisiones frente al proyecto minero han sido fruto de procesos de deliberación, variable que presenta la mayoría de aspectos que la teoría establece: distribución de la información, gestión del conflicto, influencia en la opinión pública, generación de propuestas diferentes a las de la esfera política y la influencia de la identidad, produciendo a partir de esto decisiones de tipo organizativas, de difusión, visibilidad de la problemática y decisiones de tipo legal, todas ellas con alta percepción del consenso por parte de los entrevistados.

A partir de la investigación se puede destacar que si bien en las asambleas se registran procesos deliberativos, las mediaciones no están centradas en la racionalidad, ni la capacidad argumentativa. En contraste, los debates están mediados por la identidad local, el sincretismo religioso, esferas sociales rutinarias del mundo de la vida que vienen a reforzar o socavar los acuerdos de las asambleas comunitarias. En el caso de Tetela se corrobora el postulado de Elster (2001) que hace referencia a los valores compartidos y acuerdos simbólicos del lenguaje, lo verbal y lo corporal, como condiciones propicias para la existencia del diálogo.

Los debates en la asamblea tienen un anclaje moral importante, en tanto que hay una fuerte participación de las mujeres de la comunidad como propulsoras de la resistencia y una baja participación de los jóvenes en el movimiento. Por otra parte, el papel del Estado como ente regulador también ha sido cuestionado desde la comunidad, de modo que la desconfianza frente a las instituciones fortaleció el surgimiento de espacios alternos para discutir lo que atañe al territorio.

En el conflicto suscitado en Tetela de Ocampo también se evidenció un claro enfrentamiento político entre la comunidad y el gobierno estatal. En este sentido, los espacios deliberativos y la formación de posturas en resistencia se han visto fortalecidos por una fuerte desconfianza frente a las instituciones que deben velar por los derechos de las comunidades y por el impacto que tienen los proyectos mineros en la forma de vida de los pueblos y en la composición de sus territorios. 
Finalmente, pese a que la construcción de una postura colectiva frente a los proyectos mineros a través de la asamblea comunitaria depende de factores coyunturales y contextuales muy específicos que dificultan su generalización, este ejercicio contribuye a la sistematización de experiencias de comunicación comunitarias para el fortalecimiento de procesos de resistencia y de toma de decisión colectivas frente a conflictos que atañen al territorio.

\section{Referencias}

Álvarez-Gayou, J. L. (2013). Cómo hacer investigación cualitativa. Paidós Educador.

Acosta, E. A. y Díaz, M. E. (2014). Comunidad, conflicto y utopía. Universidad Iberoamericana Puebla.

Asociación Geoinnova. (15 de mayo de 2020). Minería a cielo abierto y su impacto en el medio ambiente. Geoinnova. https:// geoinnova.org/blog-territorio/mineria-cielo-abierto-impactos/

Bastidas, L., Ramírez, B., Cesín, A., Juárez, J., Martínez, D., y Vaquera, H. (2019). Las comunidades de la Sierra Norte de Puebla, Méxi$\mathrm{co}$, frente a los megaproyectos de minería. Revista de $\mathrm{El} \mathrm{Co}$ legio de San Luis, 9(18), 183-207. https://doi.org/10.21696/ rcsl9182019899

Bohman, J. (2000). Public deliberation. Pluralism, complexity and democracy. Cambridge: MITPress.

Clavijo, I. (2017). Informe industria extractiva en Puebla: Panorama del sector minero. Colaboratorio.

Comisión Nacional para el Desarrollo de los Pueblos Indígenas (2020). Informe de actividades 2020. http://informe.cndh.org.mx/ uploads/principal/2020/IA_2020.pdf

Elster, J. (2001). La democracia deliberativa. Gedisa.

Espejel, B. O. (2012). Medio ambiente, organizaciones sociales populares y conflicto en la concepción del tiempo. En M. E. Díaz y O. S. Badillo (Eds.), Interioridad, subjetivación y conflictividad Social Ponencias de la catedra Alain Touraine (pp.213223). Universidad Iberoamericana Puebla.

Galdós, L. J. (2006). Ciudadanos y esfera pública. Revista Española de Ciencia Política, (14), 47-69. https://recyt.fecyt.es/index. $\mathrm{php} / \mathrm{recp} /$ article/view/37420 
Habermas, J. (1992). Tres modelos de democracia sobre el concepto de una política deliberativa. Debats. Revista de Cultura, Poder $i$ Societat, (39), 18-21.

Habermas, J. (2011). Acción comunicativa y el mundo de la vida. En J. Habermas, Fundamentos de la sociología según la teoría del lenguaje (pp. 204, 205). Paidós Básica.

Instituto para el Federalismo y el Desarrollo Municipal, INAFED. (1 de agosto de 2020). Enciclopedia de los municipios y delegaciones de México. INAFED. http://www.inafed.gob.mx/work/ enciclopedia/EMM21puebla/municipios/21172a.html

Maldonado, M. A. (2007). La política en la teoría deliberativa. Notas sobre deliberación, decisión y conflicto. Revista Española de Ciencia Política, (16), 37-59. https://recyt.fecyt.es/index. $\mathrm{php} / \mathrm{recp} /$ article/view/37439

Mansbridge, J. (1983). Beyond Adversary Democracy. University of Chicago Press.

Martínez, B. (2012). Impacto del turismo en el desarrollo comunitario. Benemérita Universidad Autónoma de Puebla.

Martínez, M. B. (2010). ¿Puede la deliberación ser democrática? Una revisión al marco deliberativo. Revista Española de Ciencia Política, (24), 11-32. https://recyt.fecyt.es/index.php/recp/ article/view/37504

Observatorio de Conflictos Mineros en América Latina, OCMAL. (14 de abril de 2020). Conflictos mineros en México. OCMAL. https://mapa.conflictosmineros.net/ocmal_db-v2/conflicto/lista/02024200

Portal, M. A. (1997). Ciudadanos desde el pueblo: identidad urbana y religiosidad popular en San Andrés Totoltepec, Tlalpan. Universidad Autónoma Metropolitana.

Restrepo, M. C. (2016). La práctica de la deliberación en el proceso de toma de decisiones en la asamblea comunitaria. El caso de Tetela de Ocampo (2014) [Tesis de maestría no publicada]. Benemérita Universidad Autónoma de Puebla.

Secretaría de Desarrollo Social, SEDESOL. (13 de abril de 2020). Cédulas de información municipal. SEDESOL. http://www.microrregiones.gob.mx/zap/default.aspx?entra=pdzp

Sierra, T. M. (1987). El ejercicio discursivo de la autoridad en asambleas comunitarias. Publicaciones de La casa chata. 
Silva, A. (1992). Imaginarios urbanos. Bogotá y Sao Pablo: cultura y comunicación urbana en América Latina. Tercer Mundo.

Velásquez, M. C. (2011). Espirales del tiempo en los municipios de Oaxaca: asambleas, votaciones e innovaciones de la costumbre. En V. F. Pellotier, D. Dehouve y A. Hémond (Eds.), Formas de voto, prácticas de las asambleas y toma de decisiones un acercamiento comparativo (pp. 329, 341). Publicaciones de La casa chata. 